\title{
An Experimental Research On Friction And Wear Behaviour Of Compact Graphite Iron At Elevated Temperatures
}

\author{
S. Venugopal Rao, M. Venkata Ramana, A.C.S Kumar
}

\begin{abstract}
Compact Graphite iron (CGI) is mainly used in automobile engine cylinder blocks and disc brakes. CGI has interconnected by vermicular shape graphite. Melting of steel and treatment of CGI is useful for getting sound castings. In automobiles the components manufactured by CGI are exposed to friction including wear, abrasion, thermal stresses and fatigue. Friction and wear characteristics at elevated temperatures are studied in the present study. Friction tests on CGI are conducted with pin on disc wear testing machine between CGI and hard steel disc. The deviations in frictional forces and wear behaviour are observed from the experimental results. The results shows that the wear rate and frictional forces of CGI at $400^{\circ} \mathrm{C}$ and $500^{\circ} \mathrm{C}$ temperatures was strongly influenced by the variation in induced temperatures. Scanning Electron Microscopy (SEM) is used to examine CGI pins surfaces. Temperature variations during experiments are influenced the CGI coefficient of friction.
\end{abstract}

Keywords: Compact Graphite Iron, Friction, Sliding wear, High Temperature, SEM Analysis.

\section{INTRODUCTION}

Wear and friction behaviour studies of CGI cast iron will be useful in making of blow moulding mould materials and in automobile applications. Pin on disc wear testing tribometer was used to conduct wear tests. CGI samples for wear testing were taken from the prepared material and abraded against a and contact time were taken as test variables. Weight loss of the tested samples was measured after conducting the wear tests at $400^{\circ} \mathrm{C}$ and $500^{\circ} \mathrm{C}$. [1] CGI produced with addition of alloys in the melt to charge. Carbon content is adjusted by adding graphite and after reaching required level of carbon the melt is heated up to $1530^{\circ} \mathrm{C}$ and treated with magnesium. Holding time at maximum temperature will be reduced to minimize silicon loss, melt oxidation and carbon burn will be minimized by keeping melt holding time as minimum. Modularisation with magnesium treatment and Ferro silicon inoculation have been done with a special care. Production of CGI is includes pig iron as base iron, steel scrap, graphite and Ferro silicon alloy. This CGI material is used in engine piston rings, bearings, brakes, and seals. Y.Lyu [2] studied observations which shown wear behaviour CGI overcome

Revised Version Manuscript Received on 10 September, 2019.

S. Venugopal Rao, CMR Institute of Technology,Kandlakoya, Hyderbad, Telangana, India.(Email: svgrao1 @ gmail.com)

M. Venkata Ramana, Professor of Mechanical Engineering, CVR College of Engineering, Ibrahimpatnam, Hyderabad, Telangana, India.

(Email: ramlalith@ rediffmail.com)

A.C.S Kumar, Professor of Mechanical Engineeringm, JBIET, Hyderabad, Telangana, India. (Email: acskumar2@gmail.com) hardened steel disc (EN 31). Sliding velocity, frictional force

other cast iron materials. Heat treatment processes like induction hardening will increase the wear behaviour of CGI. [3] Grey cast iron is the material which has been used in the applications where wear is considered primly. Dark graphite and bright pearlite matrix structure ferrite is observed. The distribution of graphite contains perlite and ferrite. Mo content is one of the important for the varying pearlite fraction. [4]Production rates and costs are depends on mould materials and its surfaces. [5] Nano crystalline oxide layers called glaze layers are response to low wear rates. Glaze layers are developed between pin and disc metal in pin on disc test. The CGI metal properties like wear resistance, corrosion resistance, machinability and temperature resistance can be improved by addition of copper, molybdenum, chromium, nickel and zirconium in the melt. From the wear spheroidal graphite iron experiment D. Gowda.[6]given that coefficient of friction and wear rates were measured and made conclusions that at initial time coefficient of friction varies and later converge to certain values due to the wear debris. The wear debris generated between pins and disc surface. Spheroidal graphite iron (SGI) shown high wear rates in dry and wet experimental conditions and graphite acts as lubricant.Sugwon Kim (10) studied wear behaviour of compacted graphite cast iron at elevated temperatures and results indicated that CGI can use in high temperature applications. High temperature abrasive wear properties of CGI and SGI cast irons have been studied by by E. Faculty [7] and concluded that SGI shown high wear losses than CGI, in abrasive conditions SGI is more useful. Strain ageing of subsurface layer during wear experiment at $150^{\circ} \mathrm{C}$ is the reason for increase in wear resistance CGI and SGI. Critical thickness of CGI casting, magnesium content in CGI and oxygen activity are influence the control of crystallization of graphite [8]G. Cui.[9] studied tribological properties of materials and concluded that hardness and solid lubricants like Ag, molybdates, chromates will influence the tribological properties of materials.M.S Skoinski[10] Conducted experiments at $290^{\circ} \mathrm{C}, 340^{\circ} \mathrm{C}$ and $390^{\circ} \mathrm{C}$ and concludes that CGI wear resistance is increased by decrease in abrasive as austempering temperature increased. [11] Interactions between metal particles are observed particularly due to the abrasive components of the friction material, like hard oxide particles, MgO. Plastic deformation and oxidative wear are dominantly observed at elevated temperatures. 
These deformations are analysed by Scanning Electron Microscopy and Electro Discharge Spectroscopy. Finer dispersion and coarser dispersions of graphite morphology observed at $150{ }^{\circ} \mathrm{C}$ and $250{ }^{\circ} \mathrm{C}$ respectively [12], [13]. Dry sliding wear have experimented with different materials and concluded that lubrication will change the wear behaviour at various temperatures. I.Riposan [14] has been experimented the wear at $25^{\circ} \mathrm{C}$ on metals with various lubricants and studied the surface morphology.

[15] Mathematical formulations are developed for wear protective layers. Sliding wear processes are studied between 20 to $600{ }^{\circ} \mathrm{C}$ for various metal layers.

\section{EXPERIMENTAL PROCEDURE \& RESULTS}

CGI material is manufactured and the required specimens composition is depicted in Table 1 . All elements in the table 1 are taken on weight basis. Dimensions of the specimen are $10 \mathrm{X} 12 \mathrm{~mm} 2$. Pin-on-disc wear tester is used to conduct wear tests.

Tule 1 cai conposition furts

\begin{tabular}{|l|l|llll|l}
\hline$C$ & 9 & $N_{n}$ & $p$ & $S$ & $M_{8}$ & $M_{0}$ \\
\hline $1.60-3.80$ & 2.302 .36 & 0.013 & 0.041 & 0.0024 & 0.008 & 0.002
\end{tabular}

Sliding wear and frictional forces are analysed after testing the samples $400^{\circ} \mathrm{C}$ and $500^{\circ} \mathrm{C} .25 \mathrm{~N}$ loads are applied at both the temperatures of $400^{\circ} \mathrm{C}$ and $500^{\circ} \mathrm{C}$. Table 2 indicates the test parameters. Surfaces of tested specimen are analysed for wear cracks.

Table 2. CGI Wear testing parameters

\begin{tabular}{lll}
\hline Parameters & $400^{\circ} \mathrm{C}$ & $500^{\circ} \mathrm{C}$ \\
\hline Load (N) & 25 & 25 \\
Disc speed (rpm) & 316 & 316 \\
$\begin{array}{l}\text { Track diameter } \\
(\mathrm{mm})\end{array}$ & 60 & 60 \\
$\begin{array}{l}\text { Velocity (m/s) } \\
\text { Time (s) }\end{array}$ & 1 & 1 \\
\end{tabular}

Structural behaviour of the worn specimen surfaces were analysed by Scanning Electron Microscope (SEM). The pin samples are polished with emery sheets of 4/0, 3/0, 2/0 and $1 / 0$ grades and followed by 5 micrometre alumina disc polishing paste to remove all scratches for microstructural analysis.

Sliding wear and frictional forces are analysed after testing the samples $400^{\circ} \mathrm{C}$ and $500^{\circ} \mathrm{C} .25 \mathrm{~N}$ loads are applied at both the temperatures of $400^{\circ} \mathrm{C}$ and $500^{\circ} \mathrm{C}$. Table 2 indicates the test parameters. Surfaces of tested specimen are analysed for wear cracks.

Structural behaviour of the worn specimen surfaces were analysed by Scanning Electron Microscope (SEM). The pin samples are polished with emery sheets of 4/0, 3/0, 2/0 and $1 / 0$ grades and followed by 5 micrometre alumina disc polishing paste to remove all scratches for microstructural analysis. The worn surfaces SEM images are captured and analysed. are machined as per ASTM standards. CGI chemical

\section{RESULTS AND DISCUSSION}

Table 3. Time, Wear and Frictional Forces at $400 \mathrm{deg} \mathrm{C}$

\begin{tabular}{|c|c|c|}
\hline time 8 & wrtinuphen & inetrytiester \\
\hline 0.48 & Q4) & 4 \\
\hline 643 & 3136 & $d 7$ \\
\hline 200657 & 2027 & $d x$ \\
\hline Won & 1202 & 4 \\
\hline 30001 & 5192 & 34 \\
\hline 40004 & 114 & 191 \\
\hline Xon & $H B$ & $1 n$ \\
\hline 60001 & 1602 & 327 \\
\hline 2004 & 397 & 190 \\
\hline 100001 & 42 & 15 \\
\hline Socs & 415 & 4 \\
\hline stooss: & tas & 45 \\
\hline
\end{tabular}

Table 4.Time, Wear and Frictional Forces at $500 \mathrm{deg} C$

\begin{tabular}{|c|c|c|}
\hline$f(n e b)$ & Wartincountert) & Fintonlfartiv \\
\hline oess & s.t) & 0 \\
\hline 0.28 & 417 & 0 \\
\hline $10 \mathrm{~s}$ & 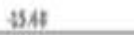 & 4 \\
\hline 100097 & +1017 & 45 \\
\hline Wos & $204 !$ & $M 2$ \\
\hline 190061 & 4192 & IIs \\
\hline b6614 & A11 & (3) \\
\hline 500026 & 34 & 923 \\
\hline 100017 & wet: & $2 n$ \\
\hline N004 & 3147 & 50 \\
\hline 100001 & 401 & (1) \\
\hline Wos & 413 & 44 \\
\hline 10000051 & 431 & 4 \\
\hline
\end{tabular}

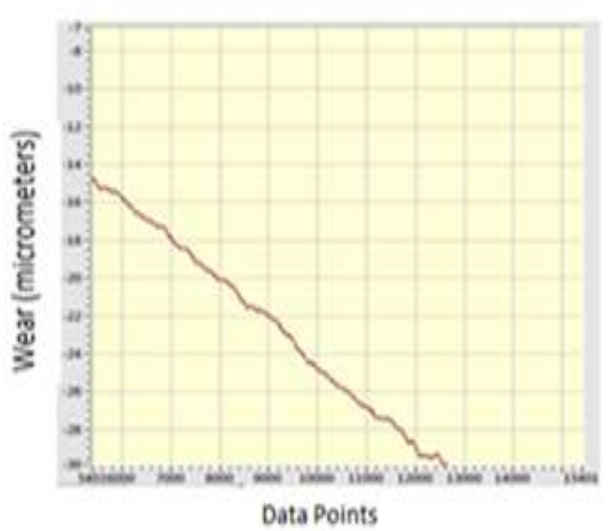

Fig 1. CGI Wear behaviour at 400 deg c temperature

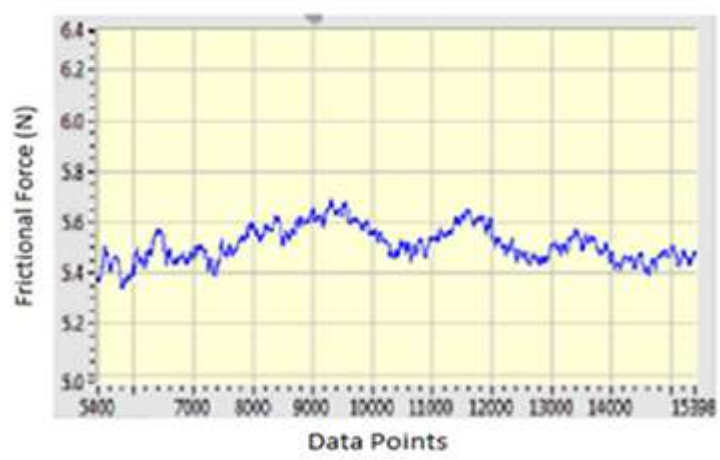

Fig 2. Frictional Force at 400 deg c temperature 


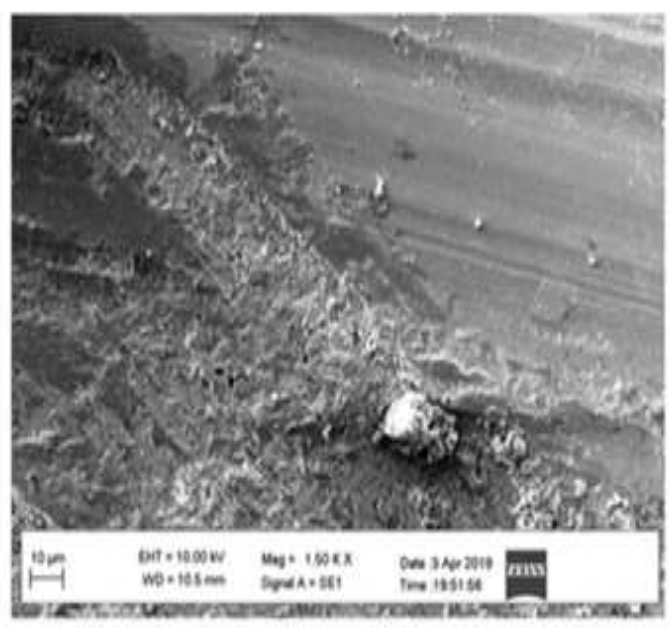

Fig 4. SEM image at 400 deg c temperature

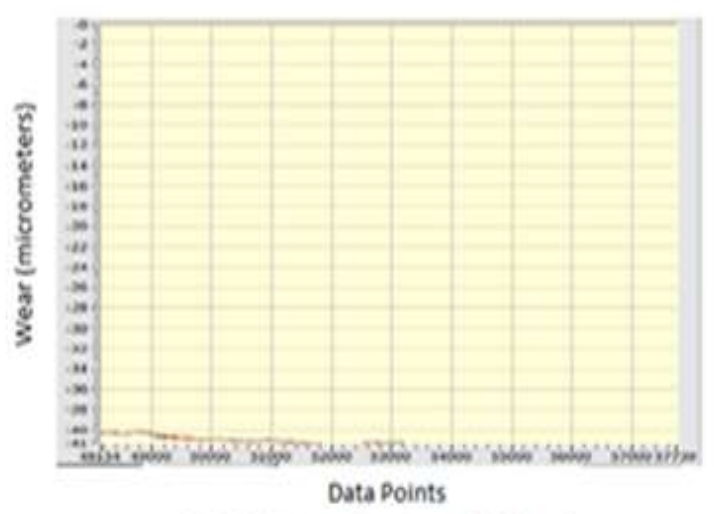

Fig.S CGI Wear behaviour at $500 \mathrm{deg} C$

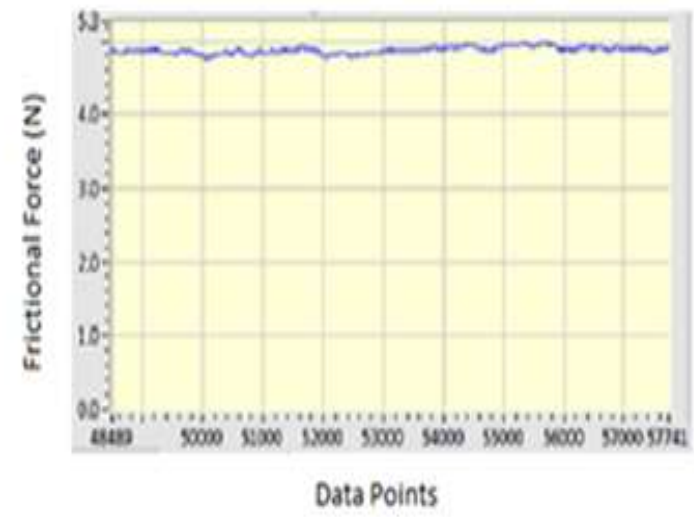

Fig.6 Frictional Forces at $500 \mathrm{deg} C$

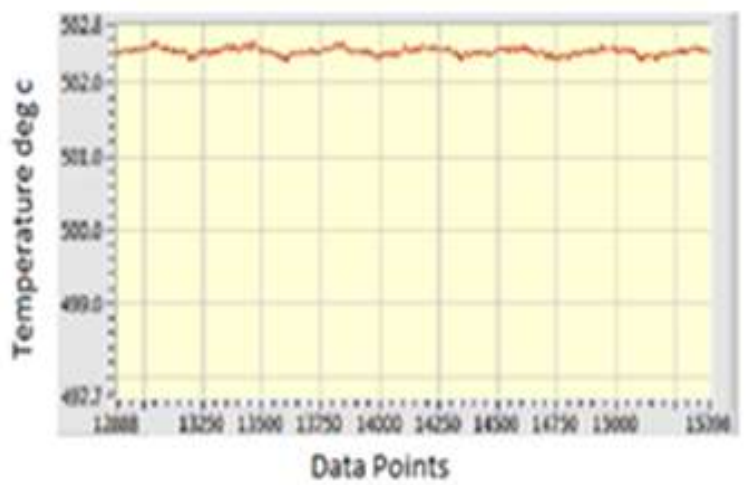

Fig 7. Temperature with time

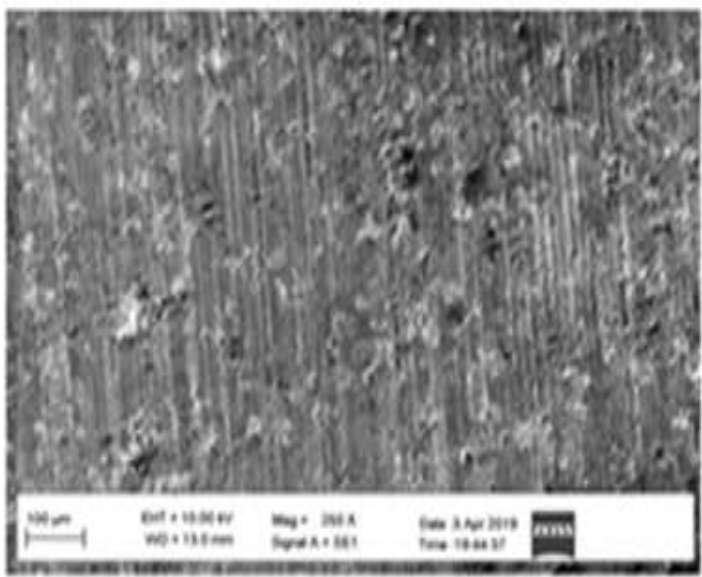

Fig.8 CGI SEM image at 500 deg C

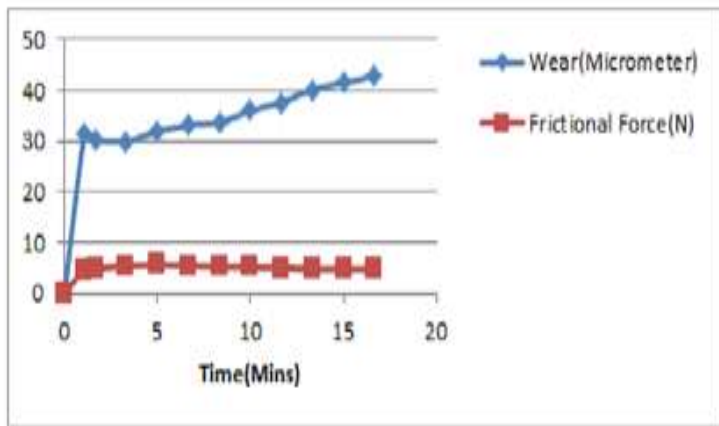

Fig 9. Wear(Micrometer), Frictional Force(N) of CGI at 400 Deg C Temperature

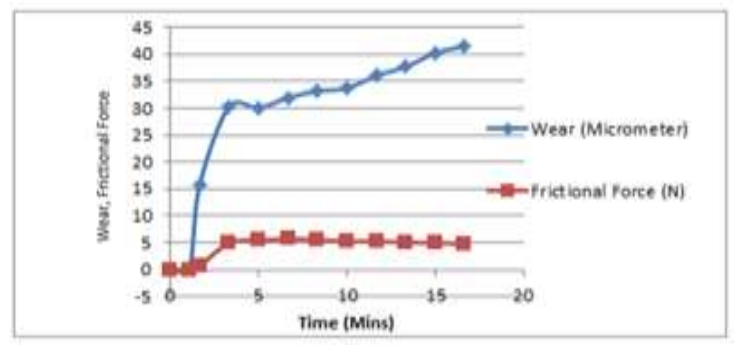

Fig 10. Wear(Micrometer), Frictional Force(N) of CGI at 500 Deg C Temperature

\section{SEM Analysis}

Fig 4 indicates the CGI pin wear image at 400 oC. Cracks in irregular fashion and voids with different volume are observed CGI pins wear surfaces. Some particles are come out from the particular region. Wear is reduced gradually as time is increased as shown in Fig 1. Carbon particles density affects the ferrous formations. Little variation in frictional force is observed as shown in Fig 2 at $400^{\circ} \mathrm{C}$. Wear characteristics decreases with variation in temperatures induced. Main reason of this declination is that graphite may not be uniformly distributed. The wear morphology of CGI sample at $500 \mathrm{oC}$ as shown in Fig 8. It is observed that lessor voids and particle deformation in $500 \mathrm{oc}$ compared to at 400oc. This observed large track formations. Pulling of carbon particles is one of the reasons for track formations. Due to high temperatures graphite particles not distributed

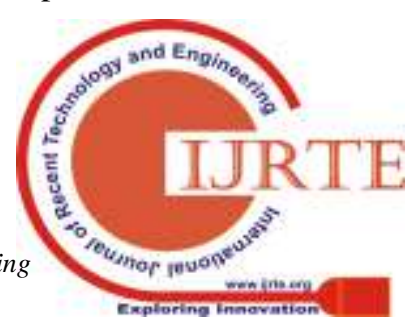


uniformly. This is due to high temperatures the bonding between graphite particles is varied. Fig. 3 and Fig. 8 indicates the temperatures from start time to end time at $400^{\circ} \mathrm{C}$ and $500^{\circ} \mathrm{C}$ respectively. High uniformity in wear is observed at $500^{\circ} \mathrm{C}$. Fig. 9 and Fig. 10 shows wear and Frictional forces are observed in small variations between 2 to 4 minutes of testing process.

\section{CONCLUSIONS}

Wear test has been conducted on CGI metal at $400^{\circ} \mathrm{c}$ and $500^{\circ} \mathrm{c}$ by using Pin-on-disc test rig Following conclusions were made from the study:

- Higher temperatures promoted higher wear rate.

- Frictional forces are slightly decreased with increasing temperature. This is due to formation of pearlite.

- More mass loss of the CGI pin material at $500^{\circ} \mathrm{c}$ temperature is observed than at $400^{\circ} \mathrm{c}$. Mass loss of CGI is observed $1.1 \mu \mathrm{m}$ at $400^{\circ} \mathrm{c} 1.3 \mu \mathrm{m}$ at $500^{\circ} \mathrm{c}$.

- Uniform weariness is observed at $500{ }^{\circ} \mathrm{C}$ and rough weariness is observed at $400^{\circ} \mathrm{c}$.

- Built up edge is observed in the surface profile at 400 ${ }^{\circ} \mathrm{C}$.

- It is concluded that wear is higher at $500^{\circ} \mathrm{c}$ is higher than at $400^{\circ} \mathrm{c}$.

\section{REFERENCES}

1. O. M. Suarez and P. Rico, "Production of Compacted Graphite Irons Through Two-Step Treatment Method," Metall. Sci. Technol., pp. 25-32, 2000.

2. Y. Lyu, "Abrasive Wear of Compacted Graphite Cast Iron with Added Tin," Metallogr. Microstruct. Anal., no. 0123456789, 2018.

3. C. Lim, "Development of Compacted Vermicular Graphite Cast Iron for Railway Brake Discs," vol. 17, no. 2, pp. 199-205, 2011.

4. D. Ag, W. Strasse, and M. Engineering, "Evaluation of Wear and Friction Mechanisms of Different Piston Ring and Cylinder Liner Materials."

5. C. Rynio, H. Hattendorf, J. Klöwer, and G. Eggeler, "The evolution of tribolayers during high temperature sliding wear," Wear, vol. 315, no. 1-2, pp. 1-10, 2014.

6. D. Gowda, C. K. D, G. M. Sandeep, and A. Parthasarathy, "ScienceDirect Tribological Characterization of Centrifugally Cast Graphite Cast Iron under Dry and Wet conditions," vol. 5, pp. 145-151, 2018.

7. H,Mindivan, Bilecik S.E. University "Study of high temperature abrasive wear behavior of vermicular and nodular cast irons," vol. 51, pp. 49-51, 2015.

8. F. Engineering, "Preparation Vermicular Graphite in Thin and Thick Wall Iron Castings," vol. 1, no. 2, pp. 41-44, 2012.

9. G. Cui, J. Han, and G. Wu, "High-temperature wear behavior of self-lubricating Co matrix alloys prepared by P/M," Wear, vol. 346-347, pp. 116-123, 2016.

10. M.S. soinski, a. jakubus, Initial assessment of abrasive wear resistance of austempered cast iron with vermicular graphite "Częstochowa university of technology, al. armii krajowej 19, 42-200 częstochowa, poland,” pp. 9-12, 2014.

11. M. Alemani a, S.Gialanella b, G.Straffelini, "Characterization and Sliding Wear Analysis of Austempered Ductile Iron," vol. 4, no. 1, pp. 1-15, 2016.

12. M. Ramadan, A. A. Nofal, and I. Elmahalawi, "of spheroidal, or ductile, graphite irons (DI), CGI has several superior characteristics such as improved castability, damping capacity and machinability. 8 The austempering transformation of CGI has been reported in the literature, 7,8-12 where the graphit," no. June, 2006.

13. E. Koraman, M. Baydoğan, S. Sayılgan, and A. Kalkanl,, "Dry sliding wear behaviour of $\mathrm{Al}-\mathrm{Fe}-\mathrm{Si}-\mathrm{V}$ alloys at elevated temperatures," Wear, vol. 322-323, pp. 101-107, 2015.

14. I. Riposan, M. Chisamera, R. Kelley, M. Barstow, and R. L. Naro, "Magnesium-Sulfur Relationships in Ductile and Compacted Graphite Cast Irons as Influenced by Late Sulfur Additions Copyright 2003 American Foundry Society," AFS Trans., vol. 093, no. 05, pp. 1-15, 2003.

15. J. Jiang, F. H. Stott, and M. M. Stack, "A generic model for dry sliding wear of metals at elevated temperatures," Wear, vol. 256, no. 9-10, pp. 973-985, 2004. 